\title{
Kirchhoff and electron curvature indexes for SiC nanoclusters
}

\author{
A.V.Luzanov \\ SSI "Institute for Single Crystals", National Academy of Sciences of \\ Ukraine, 60 Nauky Ave., 61001 Kharkiv, Ukraine
}

\section{Received March 1, 2017}

To characterize carborundum nanoclusters (nano-SiC) we employ the topological Kirchhoff index and average energy of molecular graphs. Additionally, electron-kinematic indexes which reflect an average curvature of electron paths in molecule, are invoked. The main polytypes, namely, $3 \mathrm{C}-\mathrm{SiC}$ and $2 p \mathrm{H}-\mathrm{SiC}, p=1 \div 4$, are investigated. It is established that the topological indexes make only a slight distinction between nano-SiC of the different polytypes. Quite the opposite, the electron curvature indexes provide a clear discrimination of the polytypes. In particular, the curvature indexes are ordered just in the same manner as the hexagonality measure known for such polytypes. For the electron curvatures, an effective algorithm is elaborated, allowing us to analyze nano-SiC with $10^{4}$ and more atoms even by using laptops.

Keywords: carborundum polytypes, topological indexes, quantum kinematics, resistance distances, bipartite networks, hexagonality.

Для характеризации нанокластеров карборунда (нано-SiC) использованы топологические индексы Кирхгофа и средней энергии графа. К нашему анализу привлечены также электрон-кинематические индексы, отражающие среднюю кривизну электронных путей в молекуле. Изучены нанокластеры основных политипов, а именно, 3C-SiC и $2 p \mathrm{H}-\mathrm{SiC}$, где $p=1 \div 4$. Установлено, что топологические индексы приводят к слабому дискриминированию нано-SiC различных политипов. Напротив, электронная кривизна обеспечивает четкое дискриминирование политипов. В частности, индексы кривизны, упорядочиваются точно таким же образом, как степень гексагональности соответствующих политипов. Для нано-SiC разработан әффективный алгоритм расчета электронных кривизн, позволяющий анализировать системы с $10^{4}$ и больше атомов даже с помощью ноутбука.

Індекси Кірхгофа та електронної кривини для нанокластерів SiC. А.В.Лузанов.

Щоб зхарактеризувати нанокластери карборунду (нано-SiC), використовуються топологічні індекси Кірхгофа та середньої енергії графа. До нашого аналізу залучено також електрон-кінематичні індекси, які відображають середню кривину електронних шляхів у молекулах. Вивчено нанокластери основних політипів, а саме 3C-SiC та $2 p \mathrm{H}-\mathrm{SiC}$, де $p=1 \div 4$. Встановлено, що топологічні індекси призводять до слабкого розділення кластерів нано-SiC різних політипів. Навпаки, електронна кривина забезпечує чітку дискримінацію політипів. Зокрема, індекси кривини упорядковані так само, як міра гексагональності відповідних політипів. Стосовно нано-SiC розроблено ефективний алгоритм розрахунку електронних кривин, що дозволяє за допомогою навіть ноутбука аналізувати системи $310^{4}$ та більше атомів.

\section{Introduction}

Recently, for nanoelectronics devices, new carbon-containing nanostructures have been proposed and investigated, and among them the carborundum nanoclusters (termed further as nano-SiC) have become one of leading objects [1-3]. As in the case of nanodiamonds [4,5], nano-SiC, especially their electronic properties, attract a significant 
interest owing to the potential applicability of nano-SiC in spintronics, quantum information processing, and in other fields [6-9].

It should be stressed that nano-SiC problems present special difficulties in comparison with nanodiamonds, and the so-called polytypism of carborundum crystal bodies is a main impediment to studying respective nanostructures thoroughly. Indeed, there are more than 250 polymorphic types (polytypes) for carborundum as a layered material (see p.92 in [2]). In the layered materials we have repeating structural layers, but the layer-stacking sequence of the total structure is generally varied. Clearly, the same peculiarities occur in nanostructured silicon carbides. Furthermore, for complex polytypes a number of atoms in elementary cell can be very large (up to hundreds). Happily, too complicated structures are not important for practical use. However, even in the case of simple polytypes one needs to investigate the finite-size nanostructures with hundreds and thousands atoms in order to model realistic nanoparticles more or less satisfactorily.

Under these circumstances, we must recourse to quite simplistic approaches that allow us to grasp, at least qualitatively, typical structural features of complex aggregates. Such a philosophy is adopted in the present paper in which we propose a certain electron-geometrical characterization of typical SiC nanoclusters. For this aim we make using the classical topological index due to Kirchhoff, as well as one suitable quantum chemistry characteristics (average electronic curvature) which we earlier introduced for quantifying molecular complexity $[10,11]$. A preliminary and very restricted usage of the electronic curvature for nano-SiC was given recently in our brief article [12].

\section{Kirchhoff topological index}

In this section we give notations and definitions needed for computations of the usual Kirchhoff index. Notice that there is a vast literature on topological methods for molecular structures [13, 14], and many current papers are dedicated to the graphtheoretic approach to the molecular "resistance distances" based on the so-called Kirchhoff index (see, e.g., [15, 16]). The combinatorial Laplacian matrix is used for this purpose [17], leading to a suitably formalized theory of electric networks due to Kirchhoff. The papers $[15,16,18]$ had caused a new surge of interest in this field.
For the recent results of the Kirchhoff index theory see [19].

Notice, however, that conventional topological schemes are rather restricted in principle, as taking no account of many essential details of chemical structure (atomic electronegativity, nature of chemical bonds etc.). At the same time, similar topological entities (especially the combinatorial Laplacian) appeared previously in mathematical models of phase transitions and dynamics of polymer molecules within socalled Gaussian model [20-22].

Passing to the computational aspects, we introduce the standard adjacency matrix $A_{\text {top }}$ (topological matrix) of the graph or network in question. Namely, for the given graph with $N$ nodes (vertices), $A_{t o p}$ is the $N \times N$ square matrix whose $(i, j)$ th element is

$$
\left(A_{t o p}\right)_{i j}=1, \text { iff, } i \sim j
$$

where $i \sim j$ signifies that $i$ and $j$ are the connected nodes. The usual Huckel matrix is just of this type. Slightly less familiar is the combinatorial Laplacian $L$ having matrix elements of the form

$$
L_{i j}=L_{i i} \delta_{i j}-\left(A_{t o p}\right)_{i j}
$$

where

$$
L_{i i}=\sum_{j}\left(A_{t o p}\right)_{i j}
$$

is the node degree (its "valency"). The reader can find more details about Laplacian matrices in review [17]. In particular, $L$ is a positive semi-definite, more exactly, a singular matrix because it has a single zero eigenvalue due to the evident property: $\sum_{j} L_{i j}=0$ for each $i$.

In computing the topological Kirchhoff index $\left(R_{K i r}\right.$ in the present paper) we follow the spectral representation of $R_{K i r}$, given in the above cited papers. Let us define the Laplacian spectrum as a decreasing set $\left\{\mu_{1}\right.$, $\left.\mu_{2}, \ldots, \mu_{N-1}\right\}$ of all nonzero eigenvalues of $L$ (that is, $\mu_{N}$ is excluded). Then, up to a factor, $R_{K i r}$ is a sum of their reciprocals. For our purposes, we apply a suitable scale factor, so that the working expression for the reduced (average) Kirchhoff index which we shall use below is

$$
R_{K i r}=(1 / N) \sum_{1 \leq j \leq N-1} 1 / \mu_{j}
$$


Remark that $R_{K i r}$ and a similar quantity defined in [22] can be treated as a graphtheoretic measure of total connectivity of the network under study. Additionally, physics-like interpretation of $R_{K i r}$ can be based on Kirchhoff theory of electric nets in modern language. Namely,

$$
N^{2} R_{K i r}=\sum_{i<j} R_{i j},
$$

where quantities $R_{i j}$ are explicitly expressible in terms of pseudoinverse $L^{\#}$, and can be treated as the effective resistances (resistance distances) between nodes $i$ and $j$.

\section{Curvature indexes in topological approximation}

As mentioned, the electron curvature indexes were proposed for molecules more than 20 years ago [10, 11], but their usage have been limited to few examples of applications. As we will see later, carborundum nanoclusters is a gratifying example of the curvature analysis in the topological (graphtheoretic) approximation.

Following [11]), we exploit the average curvature index ( $K$-index $)$ in a modified form. By the definition adopted here, $K$-index is a full matrix trace of the squared root of the first-order curvature operator $|\mathbf{P} \wedge \mathbf{F}|$, with $\mathbf{P}$ being a linear momentum operator, and $\boldsymbol{F} \equiv \dot{\boldsymbol{P}}$ its time derivative. We will also invoke a high-order curvature characteristic which is produced by the second-order time derivative

$$
\boldsymbol{T} \equiv \ddot{\boldsymbol{P}}
$$

Again, as in the case of Kirchhoff index (4), we will deal with the average values of curvatures. Thus we employ the following curvature indexes:

$$
K=\operatorname{Tr}|\boldsymbol{P} \wedge \boldsymbol{F}|^{1 / 2} / N,
$$

and

$$
K_{[2]}=\operatorname{Tr}|\boldsymbol{F} \wedge \boldsymbol{T}|^{1 / 2} / N
$$

In practice, the such modified (by using the sqrt operation) curvature indexes are more suitable for large-scale structures, as the previous results for carbon nanotubes have confirmed this [23].

Further, to be more precise, we must specify more details of the computational model we use. In the topological approximation to the molecular kinematics $[10,11]$, we identify one-electron Hamiltonian matrix $h$ with adjacency matrix (1):

$$
h=A_{t o p}
$$

Then the momentum Cartesian components, $P_{x}, P_{y}, P_{z}$, and their time derivatives (the electronic force components) are easy to be computed by the standard matrix commutations with the Hamiltonian:

$$
\boldsymbol{P}=h \hat{\boldsymbol{r}}-\hat{\boldsymbol{r}} h, \quad \boldsymbol{F}=h \boldsymbol{P}-\boldsymbol{P} h, \quad \boldsymbol{T}=h \boldsymbol{F}-\boldsymbol{F} h,(8)
$$

where $\hat{\boldsymbol{r}}$ is the matrix of position operator; an unimportant imaginary unit factor is omitted in Eq. (8). Matrix $\hat{\boldsymbol{r}}$ is simply formed to be a diagonal matrix of the usual Cartesian coordinates $\mathbf{R}_{i}$ of all atomic nodes $(i=1,2, \ldots N)$ :

$$
\hat{(\boldsymbol{r}})_{i j}=\boldsymbol{R}_{i} \delta_{i j}
$$

(for more detail see also [24]).

It is worth reminding that according to [10, 11], the electronic curvature indexes are a possible tool for quantifying a structural complexity of the studied molecular systems. In particular, $K$ and $K_{[2]}$ reflect a nonlinear (in a kinematic sense) character of electron movement in nanoclusters treated in a discrete (nodal) representation. As a consequence, linear chains are the structurally simplest systems because in them $K=K_{[2]}=0$.

\section{Computational details}

Before reporting the results obtained here, it is appropriate to specify the main objects of study. These are the nanostructures derived for the most important SiC polytypes. In naming the polytypes we use the standard nomenclature due to Ramsdell: $3 \mathrm{C}-\mathrm{SiC}$ for the cubic polytype, and $\mathrm{pH}-\mathrm{SiC}$ ( $p$ is integer) for the hexagonal polytypes. In our study of SiC nanoclusters we have restricted ourselves to $3 \mathrm{C}$ and hexagonal $\mathrm{pH}$ polytypes with $p=2,4,6$ and 8 . Throughout the paper we employ an idealized model geometry which is based on quite a realistic geometry of bulk SiC polytypes. For convenience, we have relegated most technical details (building of primitive cells etc) to the appendix A. In practical computations, it is sensible to scale all atomic coordinate $\mathbf{R}_{i}$. Namely, for clusters of all polytypes we make the same replacement $\mathbf{R}_{i} \rightarrow \mathbf{R}_{i} / a$ where $a=4.3602 \AA$ is the lattice constant of the cubic politype 3C-SiC. Then all curvature indexes become comparable in order of magnitude. 


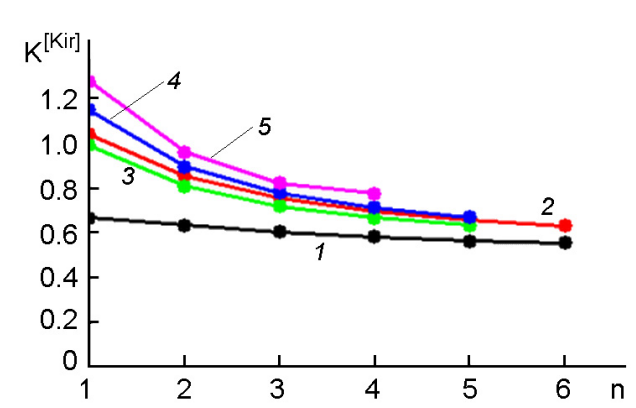

Fig. 1. Plots of the Kirchhoff index vs. the conditional length parameter, $n$, for largescale nano-SiC in various polytypes: $3 \mathrm{C}(1)$, $2 \mathrm{H}(2), 4 \mathrm{H}(3), 6 \mathrm{H}(4)$, and $8 \mathrm{H} \mathrm{(5).}$

We also significantly improved the computation scheme for curvature indexes by using the bipartite symmetry of carborundum lattices (see the full account in Appendix B). The programming and most of the computations were done within a MATHEMATICA 5.02 environment [25]. The computations for the first members of polytype series were performed on a modest laptop, and for very large clusters, with ten thousand and more atoms, a more powerful desktop was used.

\section{Indexes for large-scale nano-SiC}

We now consider the results of using the above defined indices for our main problem of interest. We look first at the obtained data for the Kirchhoff index $R_{K i r}$ (Fig. 1). We can only perceive in Fig. 1 that for cubic polytype $3 \mathrm{C}-\mathrm{SiC}$, index $R_{\text {Kir }}$ takes values which are certainly smaller than those of the rest polytypes. More interesting are the results for electron-topology curvature measures (Fig. 2). Both curvature indexes, $K$ and $K_{[2]}$, provide a clear discrimination of the large-scale nanoclusters in dependence of the prescribed polytype. Namely, in the case of curvature index $K$ the following sequence is observed:

$$
K[3 \mathrm{C}]<K[8 \mathrm{H}]<K[6 \mathrm{H}]<K[4 \mathrm{H}]<K[2 \mathrm{H}]
$$

for corresponding values of length parameter $n$ (see Eq. (A5) in Appendix A). Almost the same is valid for the high-order curvature $K_{[2]^{*}}$. We see again that for sufficiently large values of $n, 3 \mathrm{C}-\mathrm{SiC}$ clusters have the lowest calculated curvature indexes. Interestingly, Eq. (10) is precisely the same sequence which the so-called hexagonality measure $H$ generates (see chapter 2 in [2]). The known sequence for $H$ (in \%) is of the form
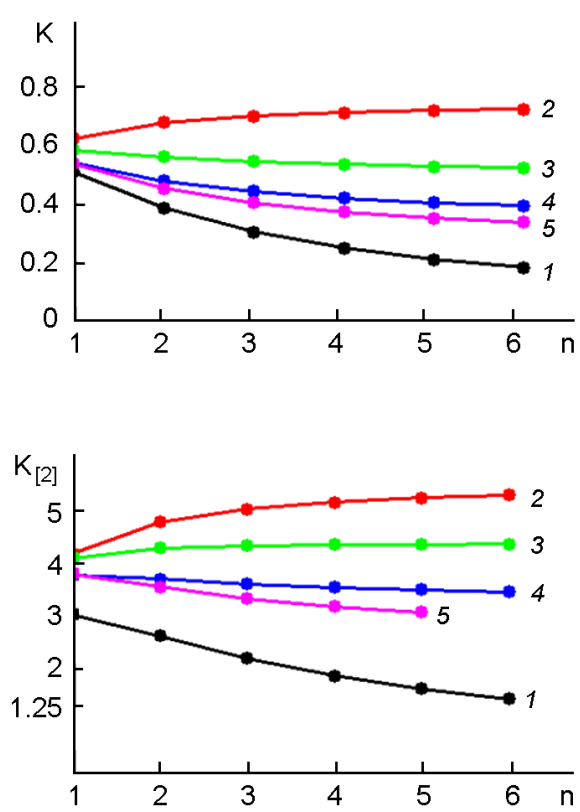

Fig. 2. Plots of curvature indexes vs. conditional length parameter $n$ for large-scale nano-SiC in various polytypes: $3 \mathrm{C}(1), 2 \mathrm{H}(2)$, $4 \mathrm{H}(3), 6 \mathrm{H}(4)$, and $8 \mathrm{H} \mathrm{(5).}$

$$
\begin{array}{r}
H[3 \mathrm{C}]=0, H[8 \mathrm{H}]=25, H[6 \mathrm{H}]=33.3, \\
H[4 \mathrm{H}]=50, H[2 \mathrm{H}]=100 .(11)
\end{array}
$$

Some physical properties, in particular, energy gap $\Delta \varepsilon$, is ordered as in Eqs. (10) and (11). The experimental $\Delta \varepsilon$ values in the bulk $\mathrm{SiC}$ are as follows [26]:

$$
\begin{gathered}
\Delta \varepsilon[3 \mathrm{C}]=2.39, \Delta \varepsilon[6 \mathrm{H}]=3.05, \\
\Delta \varepsilon[4 \mathrm{H}]=3.26, \Delta \varepsilon[2 \mathrm{H}]=3.33 .
\end{gathered}
$$

For many other semiconductors which allow the polytypism we find the similar picture (see Table 5 in the review article [27] where theoretical values of $\Delta \varepsilon$ are presented). However, it is known the systems with an opposite correlation $\Delta \varepsilon$ vs. hexagonality [28]. There are several rather sophisticated models [26, 29] (not absolutely convincing) which try to elucidate a nontrivial behavior of $\Delta \varepsilon$ in polytypic semiconductors. The problem is too intricate to be solved easily, and probably, many different aspects must be taken into account in it.

Seemingly, the electron-topological indices given here may through an additional light on this problem. For instance, the computed Kirchhoff indexes tell us about a resistance distance (in average). So we can presumably expect from Fig. 1 that $3 \mathrm{C}-\mathrm{SiC}$ polytype must be, in a sense, less resistant to electron flow than hexagonal carborun- 
dum polytypes. Analogous is the assumption that the smaller the curvature index, the greater is an electron mobility in the network (movements on more simple straight lines), all other things being equal. Thus, a essentially smaller value of the electron curvature in the cubic $\mathrm{SiC}$ is falling in line with smaller value of energy gap just in this polytype.

\section{Characterization of small nanoclusters}

Small nanoclusters are interesting perse, and here we study how small nanoclusters of the different polytypes behave in regard to the main topological and electronic characteristics. In this case we will invoke an additional quantity, topological energy (graph energy) $E_{t o p}$, which is frequently used for describing molecular graphs [30]. To calculate $E_{t o p}$ we need simply to sum up the $A_{t o p}$ eigenvalues (taken in their module); in fact this is a counterpart of the Huckel $\pi$-electron energy (for more detail see Appendix B).

The results obtained for nanoclusters with 274 and 275 atoms are given in Table 1. For convenience, in the Table all clusters are given in the same order as in corresponding hexagonality sequence (11). In the first column of Table 1 we displayed the structural images which show an evident layer-like structure of the considered systems. We see that purely topological indexes $R_{K i r}$ and $E_{t o p}$ cannot provide a clear discrimination between small nanoclusters. At the same time, electron-kinematic indexes, $K$ and especially $K_{[2]}$, present the picture which is consistent with the hexagonality percentage $H$.

\section{Conclusions}

We focused in this paper on quantification schemes which aimed at a certain electron-topology approach to discriminate $\mathrm{SiC}$ polytype structures. In reality, the atomic spatial structure of various polytypes is very similar in small-scale vicinity - main differences begin only in the third and more order of neighborhood. So, it is not a simple matter to design an universal, computationally not complicated, and sufficiently sensitive tool to distinguish clusters of different polytypes. In the present paper we made use of two types of description: the conventional topological (graph-theoretic) approach and the electron-kinematic index approach (from $[10,11])$. We expected that for the most commonly studied polytypes the graph-theoretic Kirchhoff index $R_{K i r}$ would
Table 1. Kirchhoff $R_{\text {Kir }}$, topological energy $E_{\text {top }}$, and curvature indexes $K$ and $K_{[2]}$ for small nano-SiC of various polytypes. In structural images the green color is applied for $\mathrm{C}$ atoms, and the brown color is for $\mathrm{Si}$ atoms.

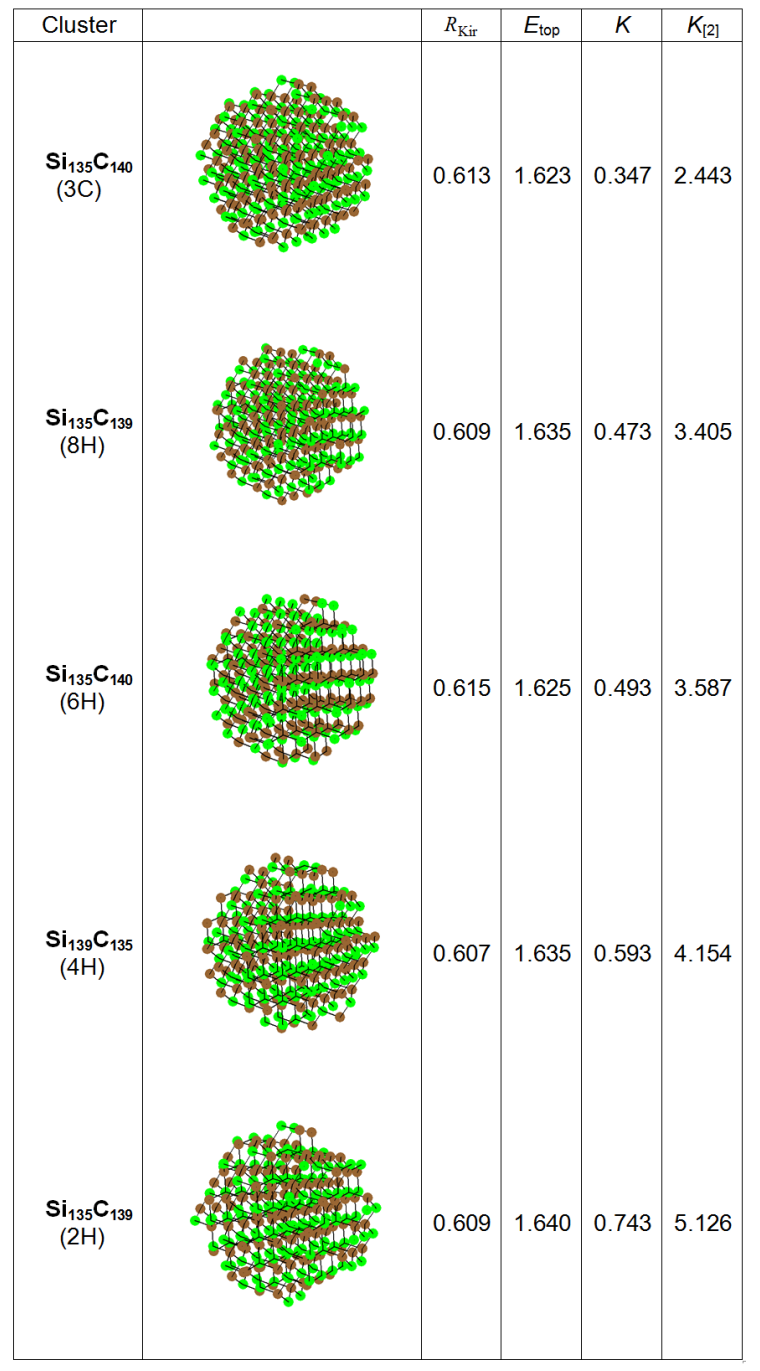

be an appropriate complexity measure. However, our computations show that by $R_{K i r}$, only the cubic SiC polytype can be clearly distinguished among other ones. The topological index $E_{t o p}$, is also not expressive, so fine distinctions between the hexagonal nanoclusters are beyond the possibilities of the topological approach itself. Concurrently, using our electron-curvature indexes proved to be a quite satisfactory way of reaching a consistent description which is in close line with the interpretation based on the hexagonality percentage.

Acknowledgement. This research was supported in part by the Ukrainian foundation of fundamental studies (Grant No. F73/107-2016). The author is also thankful to Dr.O.A.Zhikol for comments and help. 


\section{Appendix A: Building of atomic structure of ideal nano-SiC}

Here we describe the computational scheme by which we built SiC nanoclusters with an ideal geometry. By the ideal-geometry cluster we understand the one having the same atomic structure as the corresponding crystal fragment has. Thus, for constructing cluster structures, the known crystallographic SiC data (see, e.g., https://homepage.univie.ac.at/michael.leitne r/lattice/struk/b4.html) should be invoked.

First we consider the lattice of cubic 3C-SiC polytype which is similar to the well-known sphalerite lattice. The crystal basis of the $3 \mathrm{C}-\mathrm{SiC}$ primitive cell is composed of two kinds of atoms, Si and C. The corresponding crystal basis vectors $\mathbf{R}_{\mathrm{Si}}$ and $\mathbf{R}_{\mathrm{C}}$ are conventionally given in terms of the primitive translation vectors $\mathbf{a}, \mathbf{b}$ and c. The latter can be chosen in the following Cartesian representation:

$a=\frac{a}{2}(0,1,1), \quad b=\frac{a}{2}(1,0,1), \quad c=\frac{a}{2}(1,1,0)$,

where the cubic lattice constant is $a=4.3602 \AA$ for the 3C-SiC polytype. Accordingly,

$$
\boldsymbol{R}_{\mathrm{Si}}=0, \quad \boldsymbol{R}_{\mathrm{C}}=(\boldsymbol{a}+\boldsymbol{b}+\boldsymbol{c}) / 4 .
$$

The entire bulk crystal is formed by a set of all allowed translations. In the case of 3C-SiC polytype it can be cast into the form

$$
\begin{aligned}
& \boldsymbol{r}_{\mathrm{Si}}^{(i, j, k)}=\boldsymbol{R}_{\mathrm{Si}}+i \boldsymbol{a}+j \boldsymbol{b}+k \boldsymbol{c}, \\
& \boldsymbol{r}_{\mathrm{C}}^{(i, j, k)}=\boldsymbol{R}_{\mathrm{C}}+i \boldsymbol{a}+j \boldsymbol{b}+k \boldsymbol{c},
\end{aligned}
$$

where $\mathbf{r}_{\mathrm{Si}}{ }^{(i, j, k)}$ and $\mathbf{r}_{\mathrm{C}}{ }^{(i, j, k)}$ denote the neighboring nodes determined by integers $i, j$, and $k$.

In the specific computations we made a finite-size crystal region which was created by using a restricted set of $i, j, k$ integers, in Eqs. (A3) and (A4), as follows:

$$
-n \leq i, j, k \leq n,
$$

with $n$ being a certain integer. This $n$ is in fact a parameter of geometrical size of the constructed system, and in the main text it is named the length parameter of large-scale nanoclusters generated by Eqs. (A4)-(A5).

Because we have two atoms in the primitive cell of $3 \mathrm{C}-\mathrm{SiC}$ we thereby produce, by Eq. (A5), $N=2(2 n+1)^{3}$ of nodes. Generally, we have arbitrary number, $n_{\text {cell }}$, of atoms in the primitive cell, and the total number of nodes is thus

$$
N=n_{\text {cell }}(2 n+1)^{3} .
$$

When building our nano-SiC we use in practice $n \leq 6$. The clusters thus obtained will be named the initial nanoclusters. The above relations were programmed within MATHEMATICA 5.2 environment [25].

Next, we must separate out from the large-scale initial nanocluster a small symmetric nanocluster. It is also simply performed by imposing a condition on the maximal size of the required cluster (by setting a cut-off radius). The example of the obtained small clusters for $3 \mathrm{C}-\mathrm{SiC}$ is given in Table 1 of the main text. Incidentally, we remark that in the $3 \mathrm{C}-\mathrm{SiC}$ ideal nanoclusters which we construct, all Si-C bonds have the same length $\|\mathrm{Si}-\mathrm{C}\|=a \sqrt{3} / 4$ (1.888 $\AA$ if $a=4.3602 \AA)$.

Now we provide the similar procedure for hexagonal polytypes. In this case, the primitive translation vectors are of the form

$$
\begin{gathered}
a=\frac{a}{2}(1,-\sqrt{3}, 0), \quad b=\frac{a}{2}(1, \sqrt{3}, 0), \\
c=c(0,0,1),
\end{gathered}
$$

with lattice constant $a=3.076 \AA$, and $c=$ $\sqrt{8 / 3} a$ [31]. Furthermore, now $n_{\text {cell }}>2$, and we need a more general notation for all atoms of the crystal basis. Let us denote by $\mathbf{R}_{\mathrm{Si}}[\mathrm{v}]$ the position vector of the vth Si atom in the primitive cell. Then

$$
\boldsymbol{R}_{\mathrm{Si}}[v]=A_{v} \boldsymbol{a}+B_{v} \boldsymbol{b}+C_{v} \boldsymbol{c}
$$

where

$$
\left(A_{v} B_{v} C_{v}\right) \equiv v
$$

are coordinates of the $v$-th $\mathrm{Si}$ atom in the primitive translation basis. For instance, in the case of $2 \mathrm{H}-\mathrm{SiC}$ polytype, $\mathbf{1}=\left(\frac{1}{3}, \frac{2}{3}, 0\right)$, so $\mathbf{R}_{\mathrm{Si}}[1]=(\boldsymbol{a}+2 \boldsymbol{b}) / 3$. The full information concerning $v$-vectors can be founded in [31, 32]; these $v$-vectors are suitably reproduced in Table 2. For the even-order $2 p \mathrm{H}-\mathrm{SiC}$ polytypes $(p=1,2,3$, and 4$)$, counterparts of Eqs. (A3) and (A4) are of the form

$$
\begin{gathered}
\boldsymbol{r}_{\mathrm{Si}}^{(i, j, k)}=\boldsymbol{R}_{\mathrm{Si}}[v]+i \boldsymbol{a}+j \boldsymbol{b}+p k \boldsymbol{c}, 1 \leq v \leq 2 p, \\
\boldsymbol{r}_{\mathrm{C}}^{(i, j, k)}[\mathrm{v}]=\boldsymbol{r}_{\mathrm{Si}}^{(i, j, k)}[\mathrm{v}]+\frac{3}{8} \boldsymbol{c} .
\end{gathered}
$$


Table 2. Crystallographic atom-position vectors $v$ for hexagonal polytypes $2 p \mathrm{H}-\mathrm{SiC}(p=1 \div 4)$.

\begin{tabular}{|c|c|c|c|c|}
\hline $\mathbf{v}$ & $2 \mathrm{H}$ & $4 \mathrm{H}$ & $6 \mathrm{H}$ & $8 \mathrm{H}$ \\
\hline $\mathbf{1}$ & $\left(\frac{1}{3}, \frac{2}{3}, 0\right)$ & $(0,0,0)$ & $(0,0,0)$ & $(0,0,0)$ \\
$\mathbf{2}$ & $\left(\frac{2}{3}, \frac{1}{3}, \frac{1}{2}\right)$ & $\left(\frac{1}{3}, \frac{2}{3}, \frac{1}{2}\right)$ & $\left(\frac{1}{3}, \frac{2}{3}, \frac{1}{2}\right)$ & $(0,0,2)$ \\
$\mathbf{3}$ & & $\left(\frac{1}{3}, \frac{2}{3}, \frac{3}{2}\right)$ & $\left(\frac{2}{3}, \frac{1}{3}, 1\right)$ & $\left(\frac{2}{3}, \frac{1}{3}, \frac{1}{2}\right)$ \\
$\mathbf{4}$ & & $\left(\frac{2}{3}, \frac{1}{3}, 1\right)$ & $\left(0,0, \frac{3}{2}\right)$ & $\left(\frac{2}{3}, \frac{1}{3}, \frac{3}{2}\right)$ \\
$\mathbf{5}$ & & & $\left(\frac{1}{3}, \frac{2}{3} \frac{5}{2}\right)$ & $\left(\frac{2}{3}, \frac{1}{3}, 3\right)$ \\
$\mathbf{6}$ & & & $\left(\frac{2}{3}, \frac{1}{3}, 2\right)$ & $\left(\frac{1}{3}, \frac{2}{3}, 1\right)$ \\
7 & & & & $\left(\frac{1}{3}, \frac{2}{3}, \frac{5}{2}\right)$ \\
$\mathbf{8}$ & & & & $\left(\frac{1}{3}, \frac{2}{3}, \frac{7}{2}\right)$ \\
\hline
\end{tabular}

For the ideal-geometry hexagonal polytypes, the presented relations guarantee the same length $\|\mathrm{Si}-\mathrm{C}\|=\sqrt{3 / 8} a=$ $1.88366 \AA$ ) for all Si-C bonds.

\section{Appendix B: Improving computations by using bipartite symmetry of nano-SiC}

We describe now a more efficient algorithm which was specifically elaborated here for computing main curvature indexes of large-scale SiC structures. The key idea of the improvement is using bipartite symmetry of systems in question. As well known, the bipartite lattice consists of two kind of sublattices in such a way that any atom of one sublattice can be a nearest neighbor only with atoms of the second sublattice and vice versa. The plane nanographenes which we studied recently in $[33,34]$ are of this symmetry type. From the cited references we will take notations and other things which are well known due to classical works of Coulson, Hall and others. Evidently, the carborundum networks are just of this symmetry type.

We consider a standard block-matrix representation of topological matrix (1) for the bipartite graph corresponding to the given nano-SiC:

$$
h=A_{t o p}=\left(\begin{array}{cc}
0 & B \\
B^{+} & 0
\end{array}\right) .
$$

Here, block $B$ is a bond matrix, that is $B_{i j}=1$, if $i$ and $j$ are nearest-neighbor sites, otherwise $B_{i j}=0$. Simultaneously, the coordinate matrices $\mathbf{r}=(X, Y, Z)$ from Eq. (9) are block diagonal, e.g.,

$$
\begin{aligned}
& \mathrm{p}_{\mathrm{x}}=\mathrm{B} \cdot \mathrm{X}_{\mathrm{O}}-\mathrm{X}_{\star} \cdot \mathrm{B} \text {; } \\
& \mathrm{P}_{\mathrm{Y}}=\mathrm{B} \cdot \mathrm{Y}_{\mathrm{O}}-\mathrm{Y}_{\star} \cdot \mathrm{B} \text {; } \\
& \mathrm{p}_{z}=\mathrm{B} \cdot \mathrm{z}_{\circ}-\mathrm{Z}_{\star} \cdot \mathrm{B} \text {; } \\
& \mathrm{Fx}_{\star}=\mathrm{B} \cdot \stackrel{\tau}{\mathrm{p}}_{\mathrm{x}}+\mathrm{p}_{\mathrm{x}} \cdot \stackrel{\tau}{\mathrm{B}} ; \mathrm{Fx}_{\mathrm{o}}=-\left(\stackrel{\tau}{\mathrm{B}} \cdot \mathrm{p}_{\mathrm{x}}+\stackrel{\tau}{\mathrm{p}}_{\mathrm{x}} \cdot \mathrm{B}\right) ; \\
& \mathrm{FY}_{*}=\mathrm{B} \cdot \stackrel{\tau}{\mathrm{p}}_{\mathrm{Y}}+\mathrm{p}_{\mathrm{Y}} \cdot \stackrel{\tau}{\mathrm{B}} ; \mathrm{FY}_{\mathrm{O}}=-\left(\stackrel{\tau}{\mathrm{B}} \cdot \mathrm{p}_{\mathrm{Y}}+\stackrel{\tau}{\mathrm{p}_{\mathrm{Y}}} \cdot \mathrm{B}\right) ; \\
& \mathrm{Fz} z_{\star}=\mathrm{B} \cdot \stackrel{\tau}{\mathrm{p}}_{\mathrm{z}}+\mathrm{p}_{\mathrm{z}} \cdot \stackrel{\tau}{\mathrm{B}} ; \mathrm{F} z_{0}=-\left(\stackrel{\tau}{\mathrm{B}} \cdot \mathrm{p}_{\mathrm{z}}+\stackrel{\tau}{\mathrm{p}}_{\mathrm{z}} \cdot \mathrm{B}\right) ; \\
& \mathrm{t}_{\mathrm{x}}=\mathrm{B} \cdot \mathrm{Fx}_{\mathrm{O}}-\mathrm{Fx}_{\star} \cdot \mathrm{B} \text {; } \\
& \mathrm{t}_{\mathrm{y}}=\mathrm{B} \cdot \mathrm{FY_{0 }}-\mathrm{FY} \mathrm{Y}_{\star} \cdot \mathrm{B} \text {; } \\
& \mathrm{t}_{z}=\mathrm{B} \cdot \mathrm{Fz} \mathrm{z}_{\circ}-\mathrm{Fz} \mathbf{z}_{\star} \cdot \mathrm{B} \text {; }
\end{aligned}
$$

Fig. 3. Computational scheme for intermediate matrices.

$$
\begin{aligned}
& \mathrm{m}_{\mathrm{xY}}=\left(\mathrm{p}_{\mathrm{x}} \cdot \mathrm{FY}_{\mathrm{O}}+\mathrm{FY}_{\star} \cdot \mathrm{p}_{\mathrm{x}}-\mathrm{p}_{\mathrm{Y}} \cdot \mathrm{Fx}_{0}-\mathrm{Fx}_{\star} \cdot \mathrm{p}_{\mathrm{y}}\right) / 2 ; \\
& \mathrm{m}_{\mathrm{zx}}=\left(\mathrm{p}_{\mathrm{z}} \cdot \mathrm{Fx}_{\circ}+\mathrm{Fx}_{\star} \cdot \mathrm{p}_{\mathrm{z}}-\mathrm{p}_{\mathrm{x}} \cdot \mathrm{Fz}_{\circ}-\mathrm{Fz}_{\star} \cdot \mathrm{p}_{\mathrm{x}}\right) / 2 \text {; } \\
& \mathrm{m}_{\mathrm{yz}}=\left(\mathrm{p}_{\mathrm{y}} \cdot \mathrm{F} \mathrm{z}_{\circ}+\mathrm{Fz} \mathrm{z}_{\star} \cdot \mathrm{p}_{\mathrm{y}}-\mathrm{p}_{\mathrm{z}} \cdot \mathrm{FY} \mathrm{Y}_{\circ}-\mathrm{FY} \mathrm{Y}_{\star} \cdot \mathrm{p}_{\mathrm{z}}\right) / 2 \text {; } \\
& k=\mathrm{m}_{\mathrm{xy}} \cdot \stackrel{\tau}{\mathrm{m}}_{\mathrm{xy}}+\mathrm{m}_{\mathrm{zx}} \cdot \stackrel{\tau}{\mathrm{m}}_{\mathrm{zx}}+\mathrm{m}_{\mathrm{yz}} \cdot \stackrel{\tau}{\mathrm{m}}_{\mathrm{yz}} ; \\
& \tilde{k}=\stackrel{\tau}{\mathrm{m}}_{\mathrm{xy}} \cdot \mathrm{m}_{\mathrm{xy}}+\stackrel{\tau}{\mathrm{m}}_{\mathrm{zx}} \cdot \mathrm{m}_{\mathrm{zx}}+\stackrel{\tau}{\mathrm{m}}_{\mathrm{yz}} \cdot \mathrm{m}_{\mathrm{yz}} ; \\
& \left\{\mu_{j}\right\}=\text { spectrum }[k] \text {; } \\
& \left\{\tilde{\mu}_{j}\right\}=\text { spectrum }[\tilde{k}] ; \\
& K=\sum_{j=1}^{N_{*}}\left(\mu_{j}+\tilde{\mu}_{j}\right) / N ;
\end{aligned}
$$

Fig. 4. Computational scheme for curvature index $K$.

$$
X=\left(\begin{array}{cc}
X_{*} & 0 \\
0 & X_{\mu}
\end{array}\right),
$$

where diagonal matrices of atomic $x$-coordinates, $X_{*}$ and $X_{\circ}$, are relating to the first sublattice and the second sublattice, respectively. The block-diagonal structure (B2) holds as well for the force matrices $F_{x}, F_{y}$ and $F_{z}$ from Eq. (8). In accordance to Eqs. (8), (B1), and (B2), momentum matrices $P_{x}$, $P_{y}$, and $P_{z}$ reproduce the block structure of Eq. (B1):

$$
P_{x}=\left(\begin{array}{cc}
0 & p_{x} \\
p_{x}^{+} & 0
\end{array}\right) .
$$

In Figs. 3-5 we listed the full set of the needed relations which are given in the format of MATHEMATICA 5.2. In these figures the Greek letter $\tau$ above matrix symbol signifies a transposed matrix. Moreover, ad- 


$$
\begin{aligned}
& \mathrm{n}_{\mathrm{xy}}=\left(\mathrm{FY}_{*} \cdot \mathrm{t}_{\mathrm{x}}+\mathrm{t}_{\mathrm{x}} \cdot \mathrm{FY}_{\mathrm{O}}-\mathrm{Fx}_{\star} \cdot \mathrm{t}_{\mathrm{y}}-\mathrm{t}_{\mathrm{y}} \cdot \mathrm{Fx}_{\mathrm{o}}\right) ; \\
& \mathrm{n}_{\mathrm{zx}}=\left(F \mathrm{x}_{\star} \cdot \mathrm{t}_{\mathrm{z}}+\mathrm{t}_{\mathrm{z}} \cdot F \mathrm{x}_{\mathrm{o}}-F \mathrm{z}_{\star} \cdot \mathrm{t}_{\mathrm{x}}-\mathrm{t}_{\mathrm{x}} \cdot F \mathrm{z}_{\mathrm{o}}\right) ; \\
& \mathrm{n}_{\mathrm{Yz}}=\left(F z_{\star} \cdot \mathrm{t}_{\mathrm{y}}+\mathrm{t}_{\mathrm{y}} \cdot \mathrm{Fz_{0 }}-\mathrm{FY}_{\star} \cdot \mathrm{t}_{\mathrm{z}}-\mathrm{t}_{\mathrm{z}} \cdot \mathrm{F \textrm {Y } _ { 0 }}\right) ; \\
& k_{[2]}=\mathrm{n}_{\mathrm{xy}} \cdot{\stackrel{\tau}{n_{\mathrm{xy}}}}+\mathrm{n}_{\mathrm{zx}} \cdot \stackrel{\tau}{\mathrm{n}_{\mathrm{zx}}}+\mathrm{n}_{\mathrm{yz}} \cdot{\stackrel{\tau}{n_{\mathrm{yz}}}}_{\tau} ;
\end{aligned}
$$

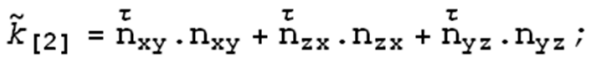

$$
\begin{aligned}
& \left\{v_{j}\right\}=\text { spectrum }\left[k_{[2]}\right] ; \\
& \left\{\tilde{v}_{j}\right\}=\text { spectrum }\left[\tilde{k}_{[2]}\right] ; \\
& K_{[2]}=\sum_{j=1}^{N_{\star}}\left(v_{j}+\tilde{v}_{j}\right) / N \text {; }
\end{aligned}
$$

Fig. 5. Computational scheme for curvature index $K_{[2]}$.

ditional symbol $N_{*}$ is used for number of atoms in the first sublattice; in so doing, $N_{*} \leq N / 2$ is implied.

For completeness, we present also the compact expression for topological energy $E_{t o p}$ (for the definition see [30]). The working expression follows from Eq. (B1):

$$
E_{\text {top }}=\operatorname{Tr}\left|A_{\text {top }}\right| / N=2 \operatorname{Tr}\left(B B^{+}\right)^{1 / 2} / N,
$$

or

$$
E_{\text {top }}=(2 / N) \sum_{j=1}^{n}\left(\lambda_{j}\right)^{1 / 2},
$$

where $\lambda_{j}$ are the usual eigenvalue spectrum of $\mathrm{BB}^{+}$. The analogous relation for alternant (bipartite) hydrocarbons within the Huckel theory was long ago obtained by Hall [35].

\section{References}

1. J.L.Fan, X.L.Wu, P.K.Chu, Progr.Mater.Sci., 51, 983 (2006).

2. Z.C.Feng, SiC Power Materials - Devices and Applications, Springer, Berlin (2004).

3. J Fan, P.K.Chu, Silicon Carbide Nanostructures: Fabrication, Structure, Springer, Berlin (2014).

4. Optical Engineering of Diamond, ed. by C.R.P.Mildren, J.R.Rabeau, Wiley, Berlin (2013).

5. Quantum Information Processing with Diamond, ed. by S.Prawer, I.Aharonovich, Elsevier LTD, Cambridge (2014).

6. A.Gali, A.Gallstrom, N.T.Son, E.Janzen, Mater. Sci. Forum, 645-648, 395 (2010).

7. A.L.Falk, B.B.Buckley, G.Calusine et al., $\mathrm{Na}$ ture Commun., 4, 1819 (2013).
8. D.J.Christle, A.L.Falk, P.Andrich et al., $\mathrm{Na}$ ture Mater., 14, 160 (2015).

9. H.Seo, A.L.Falk, P.V.Klimov et al., Nature Commun., 7, 12935 (2016).

10. A.V.Luzanov, E.N.Babich, J.Mol.Struct. (Theochem), 333, 279 (1995).

11. A.V.Luzanov, D.Nerukh, Functional Materials, 12, 55 (2005)

12. A.V.Luzanov, Vestnik Kharkiv Univ., 28, 35 (2017).

13. N.Trinajstic, Chemical Graph Theory, 2nd ed, CRC, Boca Raton, FL (1992).

14. M.V.Diudea, I.Gutman, J.Lorentz, Molecular Topology, Nova, Huntington, N.Y, (2001).

15. D.Klein, M.Randic, J.Math.Chem., 12, 81 (1993).

16. I.Gutman, B.Mohar, J.Chem. Inf.Comput.Sci., 36, 982 (1996).

17. R.Merris, Linear Algebra Appl., 197-198, 143 (1994).

18. B.Zhou, N.Trinajstic, J. Math. Chem., 46, 283 (2009).

19. W.Wang, D.Yang, Y.Luo, Discrete Appl. Math., 161, 3063 (2013).

20. G.E.Uhlenbeck, G.W.Ford, Lectures in Statistical Mechanics, AMS, Providence (1963).

21. F.H.Stillinger, E.Helfand, J.Chem.Phys., 41, 2495 (1964).

22. E.Eichinger, Macromolecules, 18, 211 (1985); Y.Yang, Macromol.Theory Simul., 7, 521 (1998).

23. A.V.Luzanov, Vestnik Kharkiv Univ., 14, 14 (2006).

24. A.V.Luzanov, E.N.Babich, Struct.Chem., 3, 175 (1992).

25. MATHEMATICA-5.2, Wolfram Research Champaign, IL (2010).

26. W.H.Backes, P.A.Bobbert, W.van Haeringen, Phys. Rev, B, 49, 7564 (1994).

27. F.Bechstedt, A.Bellabes, J.Phys.:Condens. Matter, 273201 (2013).

28. C.Raffy, J.Furthmuller, F.Bechstedt, Phys. Rev. B, 66, 075201 (2002).

29. Y-i.Matsushita, S.Furuya, A.Oshiyama, Phys. Rev. Lett., 108, 246404 (2012).

30. X.Li, I.Gutman, Graph Energy, Springer, New York (2012).

31. A.R.Verma, P.Krishna, Polymorphism and Polytypism in Crystals, Wiley, NewYork (1966).

32. L.S.Ramsdell, J.A.Kohn, Acta Cryst., 5, 215 (1952).

33. A.V.Luzanov, Functional Materials, 22, 514 (2014); A.V.Luzanov, in: Practical Aspects of Computational Chemistry IV, ed. by J.Leszczynski, M.K.Shukla, Springer, New York (2016).

34. A.V.Luzanov, F.Plasser, A.Das, H.Lischka, J. Chem. Phys., 146, 064106 (2017).

35. G.G.Hall, Proc. Roy.Soc., A229, 251 (1955). 